\title{
Evolution of the Incidence, Mortality, and Cost of Infective Endocarditis in Spain Between 1997 and 2014
}

\author{
M. Heredia-Rodríguez, $P h D^{1,2}$, A. Hernández, $M D^{7}$, Juan Bustamante-Munguira, $M D, P h D^{2,3}$, \\ F. J. Álvarez, $P h D^{2,4}$, J. M. Eiros, $P h D^{2,5}$, J. Castrodeza, $P h D^{6}$, and E. Tamayo, $P h D^{1,2}$ \\ 'Department of Anaesthesiology, Hospital Clínico Universitario, Valladolid, Spain; ${ }^{2}$ BioCritic. Group for Biomedical Research in Critical Care \\ Medicine, Valladolid, Spain; ${ }^{3}$ Department of Cardiac Surgery, Hospital Universitario Germans Trias i Pujol, Barcelona, Spain; ${ }^{4}$ Department of \\ Pharmacology, University of Valladolid, Valladolid, Spain; ${ }^{5}$ Department of Microbiology, University of Valladolid, Valladolid, Spain; ${ }^{6}$ Ministerio de \\ Sanidad, Servicios Sociales e Igualdad, Madrid, Spain.
}

KEY WORDS: Infective endocarditis; Epidemiology; Incidence; Mortality; Health care costs.

J Gen Intern Med 33(10): 1610-3

DOI: $10.1007 / \mathrm{s} 11606-018-4514-7$

(c) Society of General Internal Medicine 2018

\section{INTRODUCTION}

There is uncertainty about the magnitude of infectious endocarditis (IE), with a wide range in reported incidence (3.5 to 10 cases per 100,000 persons-year), and mortality (29 to $40 \%$ ). ${ }^{1-5}$ Discrepancies may be due to clinical and methodological differences between studies. The aging of the population, more aggressive interventions, and the increase of poverty are potentials and are possible epidemiological factors affecting IE over the last decades, particularly in Europe. The Spanish public health system is free and covers nearly all population (46.5 million inhabitants in 2017). Our aim was to assess evolution of incidence, mortality, length of hospital stay, and costs related to IE between 1997 and 2014.

\section{METHODS}

We used the Basic Minimum Data Set (BMDS) of the National Surveillance System for Hospital Data in Spain (Spanish Ministry of Health) to obtain retrospective data in all admissions for IE with hospital discharge from January 1, 1997 to December 31, 2014. Diagnoses and comorbidities were available in ICD-9 CM codes. IE was considered (421, acute and subacute endocarditis) regardless of whether it was a primary or secondary diagnosis. An anonymized dataset with demographic data (sex, age), comorbidities, associated organ dysfunction(s), Charlson's index, and mortality information was generated.

\section{RESULTS}

Overall, 34,399 patients were diagnosed with IE. The adjusted IE incidence (events per 100,000 persons) was $4.3 \%$, ranging from $3.2 \%$ in 1997 to $5.6 \%$ in 2014 (Fig. 1). Age-adjusted incidence was higher in the 7579 age group. Higher rates were observed in males than in females $(67$ v. $33 \%)$.

The Charlson Index increased from (mean \pm SD) $0.7 \pm 1.1$ in 1997 to $1.3 \pm 1.4$ in 2014. The percentage of IE patients with one, two, or three or more with organ dysfunction increased dramatically between 1997 and 2014, rising from $10.5,1.8$, and $0.2 \%$, respectively, to $25.5,6.1$, and $1.3 \%$ (Table 1).

Adjusted IE mortality (deaths per 100,000 persons) was $0.9 \%$, ranging from $0.5 \%$ in 1997 to $1.2 \%$ in 2014. Age-adjusted mortality was higher in older male patients, peaking at $4.8 \%$ in the $80-84$ age group. Higher figures were observed in males than in females.

Between 1997 and 2014, the length of hospital stay was (mean \pm SD) $28.1 \pm 24.6$ days. Hospital stay peaked (31.2 days) in 2008 and progressively declined to 26.2 days by 2014. The expenditure in the care of IE per patient increased from 6759.3 in 1997 to $15,489.6$ euros in 2008 , remaining stable from that year $(15,097.5$ euros in 2014).

\section{DISCUSSION}

The 1997 to 2014 series data from Spain shows a marked increase of incidence and more than doubled mortality due to IE. The incidence rate observed coincides with that reported in a Danish study (3.93 and 7.55 cases per 100,000 persons-year in 1994 and 2011, respectively). ${ }^{4}$

Despite medical and technological advances, IE incidence and mortality increased between 1997 and 2014 due to the older age, increased comorbidities, higher 


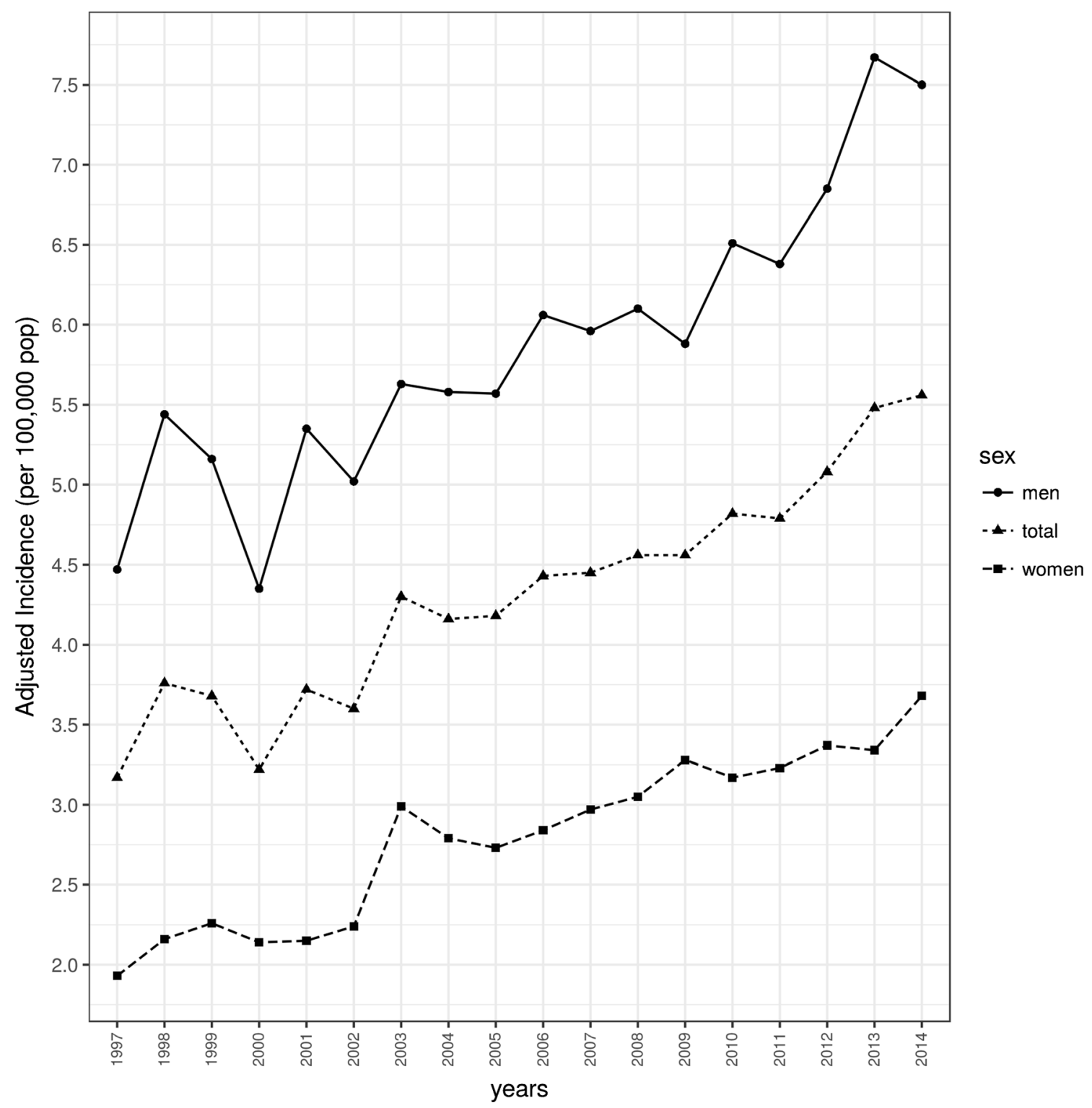

Figure 1 Population-adjusted incidence of infective endocarditis by gender in Spain between 1997 and 2014. 
Table 1 Clinical and Epidemiological Characteristics of the Patients Diagnosed with Endocarditis Between 1997 and 2014

\begin{tabular}{|c|c|c|c|c|c|}
\hline & All periods & 1997-1999 & 2000-2004 & 2005-2009 & 2010-2014 \\
\hline No. of patients & $34,399(100 \%)$ & $4239(12.32 \%)$ & $7975(23.18 \%)$ & $10,074(29.28 \%)$ & $12,111(35.20 \%)$ \\
\hline \multicolumn{6}{|l|}{ Gender } \\
\hline Male & $23,045(66.99 \%)$ & $2943(69.42 \%)$ & $5345(67.02 \%)$ & $6656(66.07 \%)$ & $8101(66.88 \%)$ \\
\hline Female & $11,353(33.00 \%)$ & $1296(30.57 \%)$ & $2629(32.96)$ & $3418(33.92 \%)$ & $4010(33.11 \%)$ \\
\hline Unknown & $1(0.00 \%)$ & $0(0.00 \%)$ & $1(0.01 \%)$ & $0(0.00 \%)$ & $0(0.00 \%)$ \\
\hline Age (years) & $61.83 \pm 18.44$ & $53.10 \pm 19.96$ & $59.24 \pm 18.43$ & $62.37 \pm 17.91$ & $66.13 \pm 16.90$ \\
\hline \multicolumn{6}{|l|}{ Comorbid condition } \\
\hline Ischemic heart disease & $1625(4.72 \%)$ & $117(2.70 \%)$ & $390(4.89 \%)$ & $549(5.44 \%)$ & $569(4.69 \%)$ \\
\hline Heart failure & $8571(24.92 \%)$ & $693(16.34 \%)$ & $1737(21.78 \%)$ & $2520(25.01 \%)$ & $3621(29.89 \%)$ \\
\hline Peripheral vascular disease & $1694(4.92 \%)$ & $91(2.15 \%)$ & $343(4.31 \%)$ & $513(5.09 \%)$ & $747(6.17 \%)$ \\
\hline Stroke & $1412(4.10 \%)$ & $145(3.42 \%)$ & $348(4.36 \%)$ & $366(3.63 \%)$ & $553(4.56 \%)$ \\
\hline Chronic lung disease & $4798(13.95 \%)$ & $318(7.50 \%)$ & $906(11.36 \%)$ & $1496(14.85 \%)$ & $2078(17.16 \%)$ \\
\hline Rheumatic disease & $554(1.61 \%)$ & $35(0.82 \%)$ & $105(1.32 \%)$ & $195(1.93 \%)$ & $219(1.80 \%)$ \\
\hline Mild liver disease & $1522(4.42 \%)$ & $131(0.32 \%)$ & $301(3.77 \%)$ & $488(4.84 \%)$ & $602(4.97 \%)$ \\
\hline Moderate-to-severe liver disease & $844(2.45 \%)$ & $71(1.67 \%)$ & $166(2.08 \%)$ & $256(2.54 \%)$ & $351(2.89 \%)$ \\
\hline Mild-to-moderate mellitus diabetes & $4685(13.62 \%)$ & $302(7.12 \%)$ & $924(11.58 \%)$ & $1493(14.82 \%)$ & $1966(16.23 \%)$ \\
\hline DM with chronic complications & $1227(3.56 \%)$ & $59(1.39 \%)$ & $212(2.66 \%)$ & $378(3.75 \%)$ & $578(4.77 \%)$ \\
\hline Chronic renal disease & $1901(5.53 \%)$ & $286(6.75 \%)$ & $642(8.05 \%)$ & $702(6.97 \%)$ & $271(2.24 \%)$ \\
\hline Hemiplegia & $608(1.76 \%)$ & $55(1.29 \%)$ & $124(1.55 \%)$ & $138(1.37 \%)$ & $291(2.41 \%)$ \\
\hline Dementia & $463(1.34 \%)$ & $33(0.78 \%)$ & $110(1.38 \%)$ & $124(1.23 \%)$ & $196(1.62 \%)$ \\
\hline Charlson Index & $1.12 \pm 1.37$ & $0.71 \pm 1.09$ & $1.04 \pm 1.34$ & $1.18 \pm 1.39$ & $1.27 \pm 1.42$ \\
\hline \multicolumn{6}{|l|}{ Acute organ dysfunction } \\
\hline Cardiovascular & $577(1.67 \%)$ & $54(1.27 \%)$ & $114(1.43 \%)$ & $169(1.67 \%)$ & $240(1.98 \%)$ \\
\hline Hematologic & $1512(4.39 \%)$ & $125(2.95 \%)$ & $306(3.84 \%)$ & $452(4.48 \%)$ & $629(5.19 \%)$ \\
\hline Hepatic & $637(1.85 \%)$ & $40(1.06 \%)$ & $105(1.32 \%)$ & $188(1.86 \%)$ & $304(2.51 \%)$ \\
\hline Neurologic & $453(1.31 \%)$ & $43(1.01 \%)$ & $113(1.41 \%)$ & $123(1.22 \%)$ & $174(1.44 \%)$ \\
\hline Renal & $6123(17.80 \%)$ & $378(8.92 \%)$ & $1081(13.55 \%)$ & $1851(18.37 \%)$ & $2813(23.22 \%)$ \\
\hline Respiratory & $584(1.69 \%)$ & $47(1.11 \%)$ & $122(1.53 \%)$ & $213(2.11 \%)$ & $202(1.67 \%)$ \\
\hline Metabolic & $487(1.41 \%)$ & $18(0.42 \%)$ & $63(0.79 \%)$ & $134(1.33 \%)$ & $272(2.24 \%)$ \\
\hline Heart valve surgery & $5414(15.74 \%)$ & $515(12.14 \%)$ & $1190(14.92 \%)$ & $1658(16.46 \%)$ & $2051(16.93 \%)$ \\
\hline Sepsis & $4350(12.64 \%)$ & $326(7.69 \%)$ & $910(11.41 \%)$ & $1391(13.80 \%)$ & $1723(14.23 \%)$ \\
\hline \multicolumn{6}{|l|}{ Microorganism isolated } \\
\hline Gram + & $2651(7.71 \%)$ & $206(4.86 \%)$ & $627(7.86 \%)$ & $881(8.74 \%)$ & $937(7.73 \%)$ \\
\hline Gram - & $1766(5.13 \%)$ & $123(2.90 \%)$ & $297(3.72 \%)$ & $528(5.24 \%)$ & $818(6.75 \%)$ \\
\hline Anaerobes & $27(0.08 \%)$ & $2(0.05 \%)$ & $5(0.06 \%)$ & $7(0.07 \%)$ & $13(0.11 \%)$ \\
\hline Fungi & $195(0.56 \%)$ & $19(0.45 \%)$ & $47(0.59 \%)$ & $54(0.54 \%)$ & $75(0.62 \%)$ \\
\hline Emergency admission & $28,306(82.29 \%)$ & $3549(83.72 \%)$ & $6571(82.39 \%)$ & $8274(82.13 \%)$ & $9912(81.84 \%)$ \\
\hline Re-admission & $6355(18.47 \%)$ & $671(15.83 \%)$ & $1342(16.83 \%)$ & $1854(18.40 \%)$ & $2488(20.54 \%)$ \\
\hline
\end{tabular}

Values were expressed as absolute numbers (percentage) and means (standard deviation)

DM diabetes mellitus

Charlson's index, and frequent multiple organ dysfunction. These results are in concordance with other reported by different authors.

Length of hospital stay and cost per patient increased from 1997 to 2008, slightly decreasing from that year until 2014. These results are consistent with those reported in France between 2007 and 2009, where the mean length of hospital stay was 30 days, with a mean cost per patient of 15,281 euros.

In Spain, there was not an increase of health spending consumption in terms of gross domestic product (GDP) during the covered period, and even it drop from 6.7 to $6.0 \%$ of GDP during the economic crisis (2009 to 2014).

This study suggests that epidemiological characteristics of IE have changed in Spain over the last two decades. Results of our study should encourage health authorities to reconsider preventive strategies implemented so far, with a special focus on elder patients with previous diseases, who are hospitalized and/or subjected to invasive diagnostic or therapeutic procedures.
Acknowledgements: We would like to thank the "Subdirección General del Instituto de Información Sanitaria (Ministerio de Sanidad, Servicios Sociales e Igualdad)" for providing the information on which this study was based.

Corresponding Author: Juan Bustamante-Munguira, MD, PhD; Department of Cardiac Surgery Hospital Universitario Germans Trias i Pujol, Barcelona, Spain (e-mail: jbustamantemunguira@gmail.com).

Funding Information This study was funded by the Carlos III Health Institute (PI15/01451) and the Regional Department of Health of the Autonomous Community of Castilla y León ("Gerencia de Salud, Consejería de Sanidad, Junta de Castilla y Leon") (grant number GRS: GRS 1270/A/16 and GRS 1255/A/16 to ET].

\section{Compliance with Ethical Standards:}

Conflict of Interest: The authors declare that they have no conflict of interest.

\section{REFERENCES}

1. Muñoz P, Kestler M, De Alarcon A, Miro JM, Bermejo J, RodriguezAbella H, et al. Current epidemiology and outcome of infective endocarditis: a multicenter, prospective, cohort study. Medicine (Baltimore). 2015;94:e1816. 
2. Sunder S, Grammatico-Guillon L, Baron S, Gaborit C, Bernard-Brunet A, Garot D, et al. Clinical and economic outcomes of infective endocarditis. Infect Dis (Lond). 2015;47:80-7.

3. Federspiel JJ, Stearns SC, Peppercorn AF, Chu VH, Fowler VG. Increasing US rates of endocarditis with Staphylococcus aureus: 19992008. Arch Intern Med. 2012;172:363-5.

4. Erichsen P, Gislason GH, Bruun NE. The increasing incidence of infective endocarditis in Denmark, 1994-2011. Eur J Intern Med. 2016;35:95-9.

5. Fedeli U, Schievano E, Buonfrate D, Pellizzer G, Spolaore P. Increasing incidence and mortality of infective endocarditis: a population-based study through a record-linkage system. BMC Infect Dis. 2011;11:48.
6. Estadística de Gasto Sanitario Público (EGSP). Ministerio de Sanidad, Servicios Sociales e Igualdad. Gobierno de España. https://www.msssi. gob.es/estadEstudios / estadisticas / inforRecopilaciones / gastoSanitario2005/home.htm (accessed 14.02.18.) 